\title{
OPEN TIBIAL FRACTURES
}

\author{
TREATMENT BY UNIPLANAR EXTERNAL FIXATION \\ AND EARLY BONE GRAFTING
}

ANAND J. THAKUR, JOY PATANKAR

From the Dr R. N. Cooper Municipal General Hospital, Bombay

\begin{abstract}
Seventy-nine open tibial fractures were treated with unilateral uniplanar tubular external fixators. Excellent stability allowed early weight-bearing. All comminuted fractures, with or without bone loss, and some transverse or short oblique fractures with intermediate fragments were treated by early bone grafting through a posterolateral approach.

The external fixator was dynamised as soon as periosteal callus was seen on the radiograph. Bone healing times ranged from 11 to $\mathbf{4 0}$ weeks (mean 20). Significant ankle stiffness occurred in $10.9 \%$ and leg shortening in $\mathbf{2 . 8 \%}$. Pin track infection was seen in $\mathbf{4 5 . 2 \%}$ but was easily controlled with standard management.

The external fixation frame allowed excellent functional freedom for Oriental patients to sit crosslegged and squat. Combined with early bone grafting, external fixation is an excellent method for the management of open tibial fractures.
\end{abstract}

External fixation has gained acceptance as the preferred method of early stabilisation for open tibial fractures. Amongst the available configurations, the unilateral uniplanar frame is being used more frequently (Behrens and Searls 1982; Hierholzer et al 1985). External fixation has been used mainly as treatment for the skin and softtissue injuries while the final phase of bone healing has been achieved in a cast or a brace which also permits weight-bearing (Nesbakken et al 1988; O'Sullivan, Chao and Kelly 1989). Opinions differ about the prolonged use of external fixation since delayed union may occur (De Bastiani, Aldegheri and Brivio 1984). Karlström and Olerud (1983) suggested the use of cancellous bone grafts in the management of cortical bone defects and delayed healing.

The present study assesses the effectiveness of unilateral, uniplanar external fixation as a definitive

A. J. Thakur, MS (Orth), FCPS, D Ortho, Consultant Orthopaedic Surgeon

Armed Forces Hospital, PO Box 1726, CPO Seeb, Sultanate of Oman.

J. V. Patankar, MS (Orth), Registrar in Orthopaedics

Children's Orthopaedic Hospital, Haji Ali Park, Bombay 400034, Republic of India.

Correspondence should be sent to Dr A. J. Thakur.

(C) 1991 British Editorial Society of Bone and Joint Surgery 0301-620X/91/3121 $\$ 2.00$

J Bone Joint Surg [Br] 1991; 73-B:448-51. method of treatment for open tibial fractures; early bone grafting was employed to overcome the possibility of delayed union.

\section{PATIENTS}

In a prospective study undertaken between December 1986 and July 1988, 79 consecutive cases of open fracture of the tibia, admitted to our unit at the Dr R. N. Cooper Municipal General Hospital in Bombay, were treated with unilateral, uniplanar double tube external fixators (Hierholzer et al 1985) as a primary and definitive method of treatment. Patients who had associated fractures involving the knee or ankle or with fractures of the femur, the contralateral tibia or the tarsal bones were excluded from the study. During this period, 3600 patients were admitted to the orthopaedic department; 1708 of them were under our care.

All our patients belonged to the lower socioeconomic group, with very poor housing and sanitation facilities. There were 66 males and 13 females; their mean age was 38 years (range seven to 71 ).

Sixty-nine patients were injured in road traffic accidents and 10 in other traumatic incidents. The softtissue injuries were classified according to Matter and Rittman (1978); 68 cases had grade II or grade III injuries (Table I). The fracture patterns were classified according 
to Bauer, Edwards and Widmark (1962) (Table II). In all, 27 patients had grade III soft-tissue injury with type III fracture (Table III).

\section{OPERATIVE TECHNIQUE}

Operation was performed as an emergency in all cases. The soft tissues were thoroughly cleaned and wounds were debrided. The fractures were reduced and stabilised by external fixation using AO/ASIF (Synthes, Robt. Mathys Co, CH 2544, Bettlach, Switzerland) tubular

Table I. Grading of the severity of the softtissue injury in 79 patients with open tibial fractures (Matter and Rittman 1978)

\begin{tabular}{cll}
\hline Grade & Injury & Number \\
\hline I & $\begin{array}{l}\text { Puncture wound from } \\
\text { within. Lesion }<5 \mathrm{~cm}\end{array}$ & 11 \\
II & $\begin{array}{l}\text { Puncture wound from within. } \\
\text { Lesion }>5 \mathrm{~cm} \text {, or trauma } \\
\text { from without with moderate } \\
\text { contusion }\end{array}$ & 31 \\
III & $\begin{array}{l}\text { Trauma from without } \\
\text { with severe contusion } \\
\text { and/or laceration }\end{array}$ & 37 \\
\hline
\end{tabular}

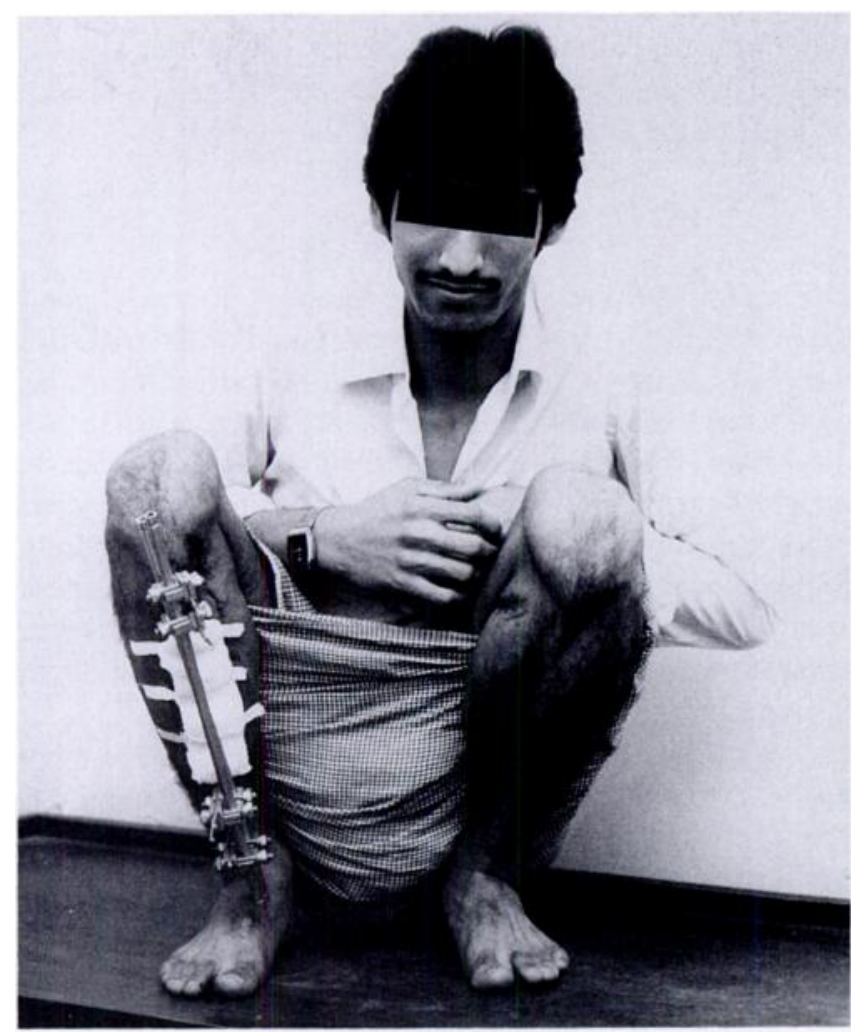

Fig. 1

Patients were able to squat at a mean of 3.8 weeks after application of an external fixator. external fixators. The technique recommended by Hierholzer et al (1985) was followed. Two Schanz screws of $4.5 \mathrm{~mm}$ diameter with short threads $(18 \mathrm{~mm})$ were placed in each major fragment in the sagittal plane. The safe corridor described by Behrens and Searls (1986) was used. An adequate skin incision was made at the site of insertion of each of the screws. The near cortex was predrilled to $4.5 \mathrm{~mm}$ and the far cortex to $3.5 \mathrm{~mm}$ using a hand drill. The Schanz screws were anchored only in the far cortex. The distance between the two screws in each fragment (pin pitch) was at least $3.5 \mathrm{~cm}$. The pin length,

Table II. Classification of fracture patterns in 79 patients with open tibial fractures (Bauer et al 1962)

\begin{tabular}{cll}
\hline Type & Patterm & Number \\
\hline I & $\begin{array}{l}\text { Spiral or long oblique } \\
\text { fracture (low energy) }\end{array}$ & 12 \\
II & $\begin{array}{l}\text { Transverse or short } \\
\text { oblique fracture with } \\
\text { or without a small } \\
\text { intermediate fragment } \\
\text { (medium energy) }\end{array}$ & 27 \\
III & $\begin{array}{l}\text { Comminuted fracture with } \\
\text { or without bone loss } \\
\text { (high energy) }\end{array}$ & 40 \\
\hline
\end{tabular}

Table III. Distribution of soft-tissue grades and fracture patterns in 79 patients

\begin{tabular}{rlll}
\hline \multicolumn{4}{l}{ Fracture pattern } \\
\cline { 2 - 4 } Grade & $\begin{array}{l}\text { Low energy } \\
\text { Type I }\end{array}$ & $\begin{array}{l}\text { Medium energy } \\
\text { Type II }\end{array}$ & $\begin{array}{l}\text { High energy } \\
\text { Type III }\end{array}$ \\
\hline I & 5 & 5 & 1 \\
II & 5 & 14 & 12 \\
III & 2 & 8 & 27 \\
\hline
\end{tabular}

the distance between the clamp and the bone, was ideally $5.5 \mathrm{~cm}$ (Evans, Kenwright and Tanner 1979). The unilateral uniplanar frame was constructed with two tubes (Fig. 1). Intrafragmental preloading was achieved by hand pressure. In four cases in which there was much bone loss, the basic assembly was reinforced by an additional frame in another plane ( $\mathrm{V}$-shaped frame of Hierholzer et al 1985).

Postoperatively the leg was maintained in elevation. In grade II and grade III injuries, the initial change of dressing was performed in the operating theatre two days after the operation. Thereafter, all wound dressings were changed daily.

Active and passive ankle and knee movements were started within 24 hours and the patients were ambulatory with crutches in three to four days. Partial weightbearing was permitted from the beginning; the load was 
gradually increased and full weight-bearing was allowed as soon as it was tolerated. Patients were encouraged to leave hospital as soon as possible having been taught how to keep the screws and the external fixator clean.

In selected cases, bone grafting from the posterior iliac crest was carried out through a posterolateral approach (Crenshaw 1987) at four to six weeks after injury. This applied to 37 of the 40 type III fractures and to seven of the 27 type II cases.

At the first radiographic indication of periosteal callus formation, the external fixator was dynamised by loosening and tightening the clamps in a cross-wise order as described by Allgöwer and Séquin (1986).

The fixators were removed stepwise. First, one tube was removed; after a few weeks, the clamps nearest to the fracture site in each fragment were loosened; the fixator was finally removed when complete bone healing had been achieved.

\section{RESULTS}

Of the 79 patients treated with external fixation, two died due to complications of their associated injuries, one required amputation and three were lost to follow-up. All these six patients had grade III soft-tissue injuries; three had type II and three had type III fractures. The remaining 73 patients were followed up for 12 to 20 months.

By the end of the first week, partial weight-bearing was achieved by all the patients. The mean time to full weight-bearing was 3.8 weeks (range 1 to 14), and the initial hospital stay averaged 2.4 weeks (range 1 to 7 ). Those re-admitted for bone grafting had an additional stay of 1.4 weeks (range 1 to 3.5 ).

Bone grafting was carried out in 44 cases $(60.3 \%)$ at an average time of 6.2 weeks (range 4 to 10) after injury.

The 73 reviewed fractures healed at an average of 20 weeks (range 11 to 40 ) after injury. The mean time spent in a frame varied with the fracture pattern is shown in Table IV.

Angular malunion between $5^{\circ}$ and $15^{\circ}$ occurred in four patients $(5.4 \%)$. Angulation of more than $15^{\circ}$ was observed in one $(1.4 \%)$. Shortening of less than $2 \mathrm{~cm}$ occurred in two legs $(2.8 \%)$. All the patients who had shortening or angular malunion had suffered high-energy fractures. Skin grafting was required in 43 patients and five required flap coverage; 16 wounds were managed by delayed primary or secondary closure. All these procedures were carried out with the external fixators in place. In the remaining nine patients, the wounds were left open and healed by epithelialisation of granulation tissue.

The wounds were healed within four weeks in 66 patients $(90.4 \%)$. In five patients the wounds healed in six weeks; in one patient in seven, and in one the wound did not heal until the tenth week.

Minor pin track infections (Green 1982), presenting as a discharge with cellulitis, were seen in 26 patients
$(35.6 \%)$. Major pin track sepsis warranting removal and re-insertion of the pin at another site occurred in seven patients (9.6\%). A short course of antibiotics was found useful. No patient developed chronic osteomyelitis at a screw site.

Lateral popliteal nerve palsy was seen in one patient, but this partially recovered during the period of observation. One patient developed a cavus deformity of the foot and clawing of the toes. Persistent oedema of the ankle and foot was seen in 11 patients. These had either undergone extensive procedures for soft-tissue coverage or had major pin track infections.

Table IV. Time to dynamisation and bone healing in three types of fracture pattern

\begin{tabular}{ccc}
\hline & \multicolumn{2}{c}{ Time in weeks (mean and range) } \\
\cline { 2 - 3 } Type & Dynamisation & Bone healing \\
\hline I & $9(5$ to 20$)$ & $16(11$ to 28$)$ \\
II & $10.1(8$ to 20$)$ & $18(14$ to 28$)$ \\
III & $17.8(8$ to 20$)$ & $26(14$ to 40$)$ \\
\hline
\end{tabular}

All the patients were able to sit cross-legged within about one week of operation and $85 \%$ were eventually able to squat for an indefinite period (Fig. 1). The remaining 11 patients, though able to squat, could do so for less than five minutes. These patients all had persistent oedema of the ankle and foot.

\section{DISCUSSION}

Unilateral, uniplanar external fixation provided good early stability so that our patients could walk with full weight-bearing at a mean 3.8 weeks after injury as compared to 30 weeks following plate and screw fixation of similar tibial fractures (Clifford et al 1988). Early weight-bearing and our patients' ability to squat and sit cross-legged on the ground for the activities of their daily living allowed early discharge from hospital. Since these are distinct advantages over other methods of treatment, external fixation has become a readily acceptable form of treatment in our community.

We treated all high-energy fractures by delayed bone grafting (Burgess et al 1987). Seven patients with mediumenergy fractures were also treated by bone grafting because, at the end of six weeks, they still had local tenderness, pain at the fracture site on axial loading and absence of callus on the radiograph. This policy resulted in a short, average healing time.

Our results compare well with those of other series of similar fractures treated by external fixation (Karlström and Olerud 1983; Nesbakken et al 1988). They also compare well with the results reported by 
Clifford et al (1988) who used plate fixation for open tibial fractures. They found union at 20 weeks in $55.7 \%$ of patients and at 30 weeks in $79.5 \%$; these figures compare with $76.7 \%$ and $97.3 \%$ respectively in our series. Our incidence of ankle stiffness $(10.9 \%$ ) was low compared to the $30.7 \%$ reported by Nesbakken et al (1988) and the $20.8 \%$ of Clifford et al (1988).

We conclude that unilateral, uniplanar external frame fixation with early bone grafting is considered the best method of management for open tibial fractures in our community.

The authors would like to thank Dr K. M. Abdelbasit from the Department of Mathematics and Computing, Sultan Qaboos University, Muscat, for his guidance on statistical analysis of the data.

No benefits in any form have been received or will be received from a commercial party related directly or indirectly to the subject of this article.

\section{REFERENCES}

Allgöwer M, Séquin F. Dynamization of the AO/ASIF tubular external fixator. AO/ASIF Dialogue 1987; 1(3):12-3.

Bauer GCG, Edwards P, Widmark PH. Shaft fractures of the tibia: etiology of poor results in a consecutive series of 173 fractures. Acta Chir Scand 1962; 124:386-95.
Behrens F, Searls K. Unilateral external fixation experience with the ASIF "Tubular" frame. In: Uhthoff HK, ed. Current concepts of external fixation of fractures. Berlin, etc: Springer-Verlag, 1982: 177-83.

Behrens F, Searls K. External fixation of the tibia: basic concepts and prospective evaluation. J Bone Joint Surg [Br] 1986; 68-B:246-54.

Burgess AR, Poka A, Brumback RJ, et al. Management of open grade III tibial fractures. Orthop Clin North Am 1987; 18:85-93.

Clifford RP, Beauchamp CG, Kellam JF, Webb JK, Tile M. Plate fixation of open fractures of the tibia. J Bone Joint Surg [Br] 1988; 70-B :644-8.

Crenshaw AH. Ed. Surgical approaches. In: Campbell's operative orthopaedics. 7th ed. St Louis, etc: CV Mosby Co, 1987:23-107.

De Bastiani G, Aldegheri R, Brivio LR. The treatment of fractures with a dynamic axial fixator. J Bone Joint Surg [Br] 1984; 66-B :538-45.

Evans M, Kenwright J, Tanner KE. Analysis of single-sided external fracture fixation. Eng Med 1979; 8:133-7.

Green SA. Complications of external fixation. In: Uhthoff HK, ed. Current concepts of external fixation of fractures. Berlin, etc: Springer-Verlag, 1982:43-52.

Hierholzer G, Rüedi T, Allgöwer M, Schatzker J. Manual on the $A O /$ ASIF tubular external fixator. Berlin, etc: Springer-Verlag, 1985.

Karlström G, Olerud S. External fixation of severe open tibial fractures with the Hoffmann frame. Clin Orthop 1983; $180: 68-77$.

Matter P, Rittmann W-W. The open fracture: assessment, surgical treatment and results. Berne, etc: Hans Huber, 1978.

Nesbakken A, Alho A, Bjersand AJ, Jensen DK, Stangeland L, Walloe A. Open tibial fractures treated with Hoffman external fixation. Arch Orthop Trauma Surg 1988; 107:248-52.

O'Sullivan ME, Chao EY, Kelly PJ. The effects of fixation on fracturehealing. J Bone Joint Surg [Am] 1989; 71-A :306-10. 